\title{
12. \\ Cancers in 2010 attributable to ionising radiation exposure in the UK
}

DM Parkin*,I and SC Darby²

'Centre for Cancer Prevention, Wolfson Institute of Preventive Medicine, Queen Mary University of London, Charterhouse Square, London ECIM 6BQ, UK;

${ }^{2}$ Clinical Trial Service Unit \& Epidemiological Studies Unit, University of Oxford, Oxford, UK

British Journal of Cancer (201 I) I 05, S57-S65; doi:I0.1038/bjc.20II.485 www.bjcancer.com

(C) 201। Cancer Research UK

The hazards of exposure to some types of ionising radiation were recognized shortly after the discovery of the X-ray in 1895: by 1902 the first radiation-associated cancer was reported in a skin sore and, within a few years, a large number of such skin cancers had been observed. The first report of leukaemia in radiation workers appeared in 1911. Since then there have been many reviews of the health effects of ionising radiation, most notably in the reports of the United Nations Scientific Committee on the Effects of Atomic Radiation (UNSCEAR) (see, for example, UNSCEAR, 2006). The International Agency for Research on Cancer's Monographs on the Carcinogenic Risk to Humans also reviewed the effects of ionising radiation, both in the form of exposure to external $\gamma$ or X-rays (IARC, 2000) and as $\alpha$ and $\beta$ particles from internalised radionuclides (IARC, 2001), and all these types of radiation were classified as carcinogenic to humans.

The UK Health Protection Agency (HPA) reviews exposure to ionising radiation among the population of the UK from sources of both natural and artificial origin. A summary of their most recent evaluation is shown in Table 1. Quantitatively, radon was the most important source and contributed about half the total, followed by other sources of natural radiation (cosmic, gamma and internal) contributing about $35 \%$, and medical radiation (which included radiation received during diagnostic procedures, but excluded therapeutic irradiation) at $15 \%$.

In the present report we have estimated the number of cancers attributable to ionising radiation in the population of the UK in 2010. We have considered the sources of exposure included in the HPA's review and, in addition, we have estimated the number of second cancers associated with therapeutic radiation.

\section{METHODS AND RESULTS}

\section{Radon}

The chemically inert gas radon-222 arises from the uranium-238 present throughout the earth's crust and is a ubiquitous air pollutant. If inhaled, radon itself is mostly exhaled immediately, but its short-lived progeny are solid and tend to deposit on the

\footnotetext{
*Correspondence: Professor DM Parkin; E-mail: d.m.parkin@qmul.ac.uk
}

bronchial epithelium, where they may expose sensitive cells to alpha irradiation. Radon has been classified as carcinogenic to humans (IARC, 2001). Outdoor radon concentrations in the UK are low, but indoor concentrations are higher, especially in houses and other small buildings, and indoor radon at home is the largest source of exposure to natural ionising radiation. Gray et al (2009) used information on the distribution of measured radon gas concentrations in UK homes from a nationwide representative survey (Wrixon et al, 1988) together with estimates of the percentage increase in the risk of lung cancer per $100 \mathrm{~Bq} \mathrm{~m}^{-3}$ increase in the long-term average radon concentration at home, in people with well-documented smoking histories (Darby et al, 2005, 2006) to estimate the burden of fatal radon-induced lung cancer in the UK in 2006.

Table 2a shows the results from Gray et al (2009). Table $2 \mathrm{~b}$ shows the estimated number of cases of lung cancer caused by radon in 2010, based on the number of deaths in Table $2 \mathrm{a}$ and the total number of deaths from lung cancer in the UK in 2006 (by age group and sex). It assumes that the fraction of lung cancer cases due to radon is the same as the fraction of lung cancer deaths (that is, that the risk of death from lung cancer in lung cancer patients is the same in radon-induced cases and other cases).

The 1376 cases of lung cancer attributable to residential radon represent $3.4 \%$ of the total number of lung cancer cases estimated to have occurred in the UK in 2010 (or $0.4 \%$ of all new cancers in 2010). Of these, $57 \%$ of the radon-induced cancers occurred in individuals aged 55-74 years. Most of the remainder occurred in individuals aged over 75 , with $3 \%$ at ages $<55$ (Table $2 \mathrm{~b}$ ). Of the radon-induced lung cancers, $55 \%$ were in men. The vast majority of radon-induced lung cancers are caused jointly by radon and active smoking in the sense that the lung cancer could have been avoided by avoiding either exposure; radon alone was estimated to be responsible for only 157 deaths in $2006(0.5 \%$ of lung cancer deaths) (Gray et al, 2009). This is equivalent to 182 cases in 2010 ( $0.45 \%$ of lung cancer cases, $0.06 \%$ of all cancers).

\section{Medical exposures}

Medical exposures to ionising radiation include those for diagnostic (X-rays and nuclear medicine) and therapeutic purposes (radiotherapy). Although we are concerned here with 
Table I Summary of the Health Protection Agency's review of the annual exposure of the UK population from all sources of ionising radiation

\begin{tabular}{lcc}
\hline Source & Average annual dose $(\boldsymbol{\mu S v})^{\mathbf{a}}$ & Total (\%) \\
\hline Natural & & \\
Cosmic & 330 & 12 \\
Gamma & 350 & 13 \\
Internal & 250 & 9.5 \\
Radon & 1300 & 50 \\
& & \\
Artificial & 410 & 15 \\
Medical (diagnostic only) & 6 & 0.2 \\
Occupational & 6 & 0.2 \\
Fallout & 0.9 & $<0.1$ \\
Discharges & 0.1 & $<0.1$ \\
Consumer products & 2700 & 100 \\
Total (rounded) & & \\
\hline
\end{tabular}

Based on Hughes et al (2005). 'Throughout this report the term 'dose' is used to indicate 'committed effective dose' unless otherwise specified. 'committed effective dose' is derived by considering the absorbed dose (in joules per kilogram) and then multiplying it by a weighting factor to take account of the type of radiation involved. For sources that do not involve a uniform dose to the whole body, the doses to specific organs are further weighted according to factors recommended by the International Commission on Radiological Protection (ICRP, 2007). ${ }^{b}$ Assuming that living for a year in a home with a long-term average radon gas concentration of $20 \mathrm{Bqm}^{-3}$ gives rise to a dose of about $1000 \mu \mathrm{Sv}$.

Table 2a Lung cancer deaths in 2006 attributable to residential radon exposure in the UK

\begin{tabular}{lccr} 
& \multicolumn{3}{c}{ Number of deaths } \\
\cline { 2 - 4 } Age (years) & Males & Females & Total \\
\hline$<35$ & $\approx 0.5$ & $\approx 0.5$ & 1 \\
$35-54$ & 35 & 29 & 64 \\
$55-74$ & 312 & 216 & 528 \\
$\geqslant 75$ & 290 & 227 & 517 \\
All ages & 637 & 473 & 1110 \\
\hline
\end{tabular}

From Gray et al (2009).

evaluating the negative consequences - in terms of the number of cancer cases likely to be induced by such radiation - these should be set in the context of the substantial benefits accruing through the management of individual patients.

Diagnostic X-rays Diagnostic X-rays are the largest man-made source of radiation exposure to the general population, contributing about $15 \%$ of the total annual dose in the UK from all sources (see Table 1). Although diagnostic X-rays provide great benefits, their use involves a small risk of developing cancer. Berrington de González and Darby (2004) estimated the extent of this risk on the basis of the annual number of diagnostic X-rays undertaken in the UK. They combined data on the frequency of diagnostic X-ray use in 1991-1996, the estimated radiation doses from X-rays to individual body organs, and risk models (based mainly on the Japanese atomic bomb survivors, see UNSCEAR, 2000), with population-based cancer incidence rates from the UK in 1988-92. They estimated the attributable fraction of cases for nine types of cancer, and for all radiation-inducible cancers (i.e., all cancers except lymphomas, multiple myeloma, and chronic lymphocytic leukaemia (CLL)). In their analysis, the cumulative risks (and attributable fractions) were calculated up to age 75 . But, under the assumption that radiation-induced cancer risks persist indefinitely, the same population-attributable fractions (PAFs) should be applicable to cases occurring after age 75 .
Table 2b Estimated lung cancer cases in 2010 attributable to residential radon in the UK by age and sex

\begin{tabular}{lccc}
\hline & \multicolumn{3}{c}{ Number of cases } \\
\cline { 2 - 4 } Age (years) & Males & Females & Total number (\%) \\
\hline$<35$ & 0 & 1 & $1(<0.1)$ \\
$35-54$ & 20 & 21 & $41(3)$ \\
$55-74$ & 436 & 342 & $778(57)$ \\
$\geqslant 75$ & 302 & 254 & $556(40)$ \\
All ages & 759 & 618 & $1376(100)$ \\
\hline
\end{tabular}

Applying the PAFs calculated on the basis of radiation exposure in the mid-1990s to the cancers diagnosed in the UK in 2010 (Table 3 ) suggests that some 1861 cases, or $0.6 \%$ of all cancers, were caused by diagnostic radiation.

Nuclear medicine Small amounts of radiation are received through administration of radio-isotopes for diagnostic or therapeutic purposes. Three surveys of the frequency of different nuclear medicine procedures in the UK and the annual collective dose arising from them have been carried out by the HPA. Based on the most recent survey, which was carried out in 2003-4, the estimated total annual collective dose from diagnostic nuclear medicine procedures was 1620 man Sv, which was approximately $32 \%$ higher than at the time of the second survey in 1989 , and $67 \%$ higher than at the time of the first survey in 1982 (Hart and Wall, 2005). The 2003-4 survey was the first to consider doses from therapeutic nuclear medicine procedures, and the estimated annual collective dose to the UK population from treatment of the three commonest disorders (thyroid carcinoma, thyrotoxicosis and non-toxic goitre) was 742 man Sv. The procedures with the largest contributions to estimated collective dose ( $>50$ man Sv) in 2003-4 are shown in Table 4.

The doses to different organs of the body can be estimated on the basis of the total administered activity for different procedures and conversion factors using estimates of the dose to different organs per unit activity administered. The estimates were taken from publications of the International Commission on Radiological Protection (ICRP, 1988, 1998). Thus, for example, the effective dose of ${ }^{99} \mathrm{Tc}^{\mathrm{m}}$ phosphates is $5.7 \times 10^{-3} \mathrm{mSv} \mathrm{MBq}^{-1}$, while the dose to the bladder is $4.8 \times 10^{-2} \mathrm{mSv} \mathrm{MBq}^{-1}$ (in adults). We may therefore estimate the annual collective bladder dose in UK in $2003-4$ as $601 \times(0.048 / 0.0057)$ or 5061 man Sv.

Organ-specific dose estimates were prepared for 2003-4, 1989 and 1982, with linear interpolation for the intervening years. For years prior to 1982, we assumed the same organ-specific dose profile as in 1982, with a linear diminution in exposure back to zero in 1950, the period around which diagnostic radio isotopes were coming into medical use in UK. For the years 2005-10, we assumed the same organ-specific dose profile as in 2003-4, with the same linear change in exposure as observed in the period $1989-2003 / 4$

Figure 1 shows the estimated annual collective dose for five specific organs and also the corresponding effective dose to the whole body. These collective doses for the whole population have been converted to average doses for individuals in each age and sex group in the population by multiplying the collective doses by weights proportional to the distribution of exposure in the different age and sex groups, and then dividing by the number of people in the appropriate population at risk. The age and sex distribution of exposures to radioactive isotopes in nuclear medicine is not known; therefore, as a proxy, we assume that it is proportional to the distribution of new cases of cancer in the relevant time period. This is because most investigations occur in the context of chronic disorders (including, very often, suspected 
Table 3 Estimated cancer cases in the UK in 2010 by caused by diagnostic radiation

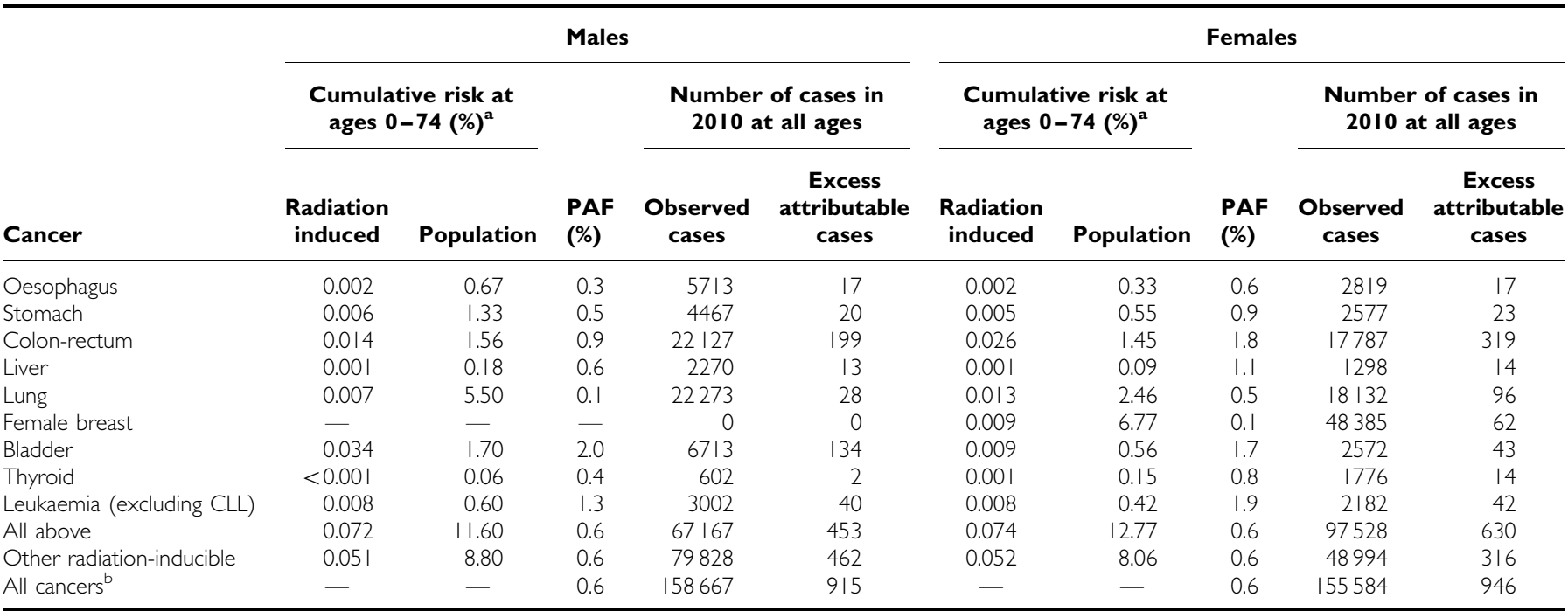

Abbreviations: $\mathrm{CLL}=$ chronic lymphocytic leukaemia; PAF = population-attributable fraction. ${ }^{a}$ Cumulative risks, based on exposures in 1991 -6, from Berrington de González

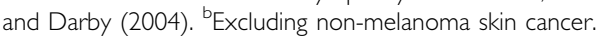

Table 4 Nuclear medicine procedures and estimated radiation doses

\begin{tabular}{|c|c|c|c|c|}
\hline & \multicolumn{2}{|c|}{ Isotope } & $\begin{array}{c}\text { Average } \\
\text { dose } \\
\text { per } \\
\text { procedure } \\
\text { (mSv) }\end{array}$ & $\begin{array}{c}\text { Annual } \\
\text { collective } \\
\text { dose } \\
2003-4 \\
\text { (man Sv) }\end{array}$ \\
\hline \multicolumn{5}{|l|}{ Diagnostic } \\
\hline Bone scan & ${ }^{99} \mathrm{Tc}^{\mathrm{m}}$ & Phosphates & 3.0 & 601 \\
\hline Myocardium & ${ }^{201} \mathrm{Tl}$ & Thallous chloride & 12.9 & 209 \\
\hline Myocardium & ${ }^{99} \mathrm{TC}^{\mathrm{m}}$ & Tetrofosmin & 3.1 & 196 \\
\hline Myocardium & ${ }^{99} \mathrm{TC}^{\mathrm{m}}$ & Sestamibi & 3.7 & 92 \\
\hline Lung perfusion & ${ }^{99} T c^{m}$ & MAA & 0.9 & 85 \\
\hline Tumours (PET) & ${ }^{18} \mathrm{~F}$ & FDG & 7.0 & 83 \\
\hline \multicolumn{5}{|l|}{ Therapeutic } \\
\hline Thyroid carcinoma & 131 & lodide & $259.0^{\mathrm{a}}$ & 437 \\
\hline Thyrotoxicosis and goiter & .131 & lodide & $29.0^{\mathrm{a}}$ & 305 \\
\hline
\end{tabular}

Abbreviations: $\mathrm{mSv}=$ milli-Sievert; man Sv= man-Sievert. Based on Hart and Wall (2005). ${ }^{a}$ Excludes dose to the thyroid.

cancer). The populations in 5-year periods were taken to be equivalent to the census at the mid-year.

Figure 2 shows the estimated average individual effective dose to the whole body, in mSv, in 1982 and 2003-4 for males and females combined.

As we wish to estimate the effect of these estimated annual doses on cancer incidence in 2010, we estimated cumulative dose for specific age groups in 2005, thereby assuming a minimum 5 -year latency between exposure and effect, as in BEIR VII (NRC, 2006). Cumulative exposures are small: $<1 \mathrm{mSv}$ before age 60, for example, and only about $6.5 \mathrm{mSv}$ (males) and $4 \mathrm{mSv}$ (females) by age 90 . To estimate the effects of such radiation for cancers other than leukaemia, we used the cancer risk estimates, expressed as excess relative risks (ERRs) per Sv, from the report of UNSCEAR (2006) as summarised in Table 5.

The ERRs in 2005, together with the estimated doses, were applied to the observed numbers of solid cancer cases in 2010, to obtain the attributable cancers. The total was small - only about 4 excess cases in each sex.

For leukaemia, the relationship between risk and exposure is more complex, as ERR depends not only on dose but also on age at exposure, and time since exposure, and varies by sex. The BEIR

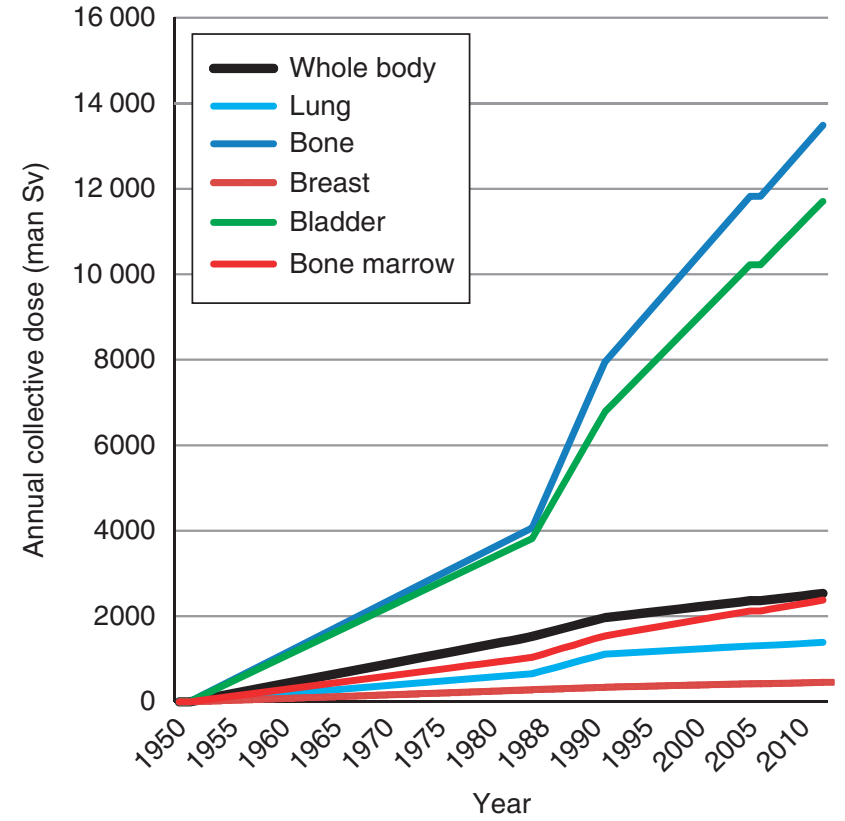

Figure I Estimated annual collective doses from nuclear medicine, for five specific organs and for the whole body. The estimate for the whole body is a weighted average of the estimates for specific organs, using the tissue-weighting factors recommended by the ICRP. These were chosen to represent approximately the relative contributions from different organs to the total number of radiation-induced cancers that would arise following uniform irradiation of the whole body (ICRP, 2007).

VII report (NRC, 2006) used a model that expressed ERR as a linear-quadratic function of dose, with allowance for dependencies on sex, age at exposure and time since exposure. The preferred model took the form:

$$
\mathrm{ERR}=\beta D(1+\theta D) \exp \left[\gamma e^{*}+\delta \log (t / 25)+\phi e^{*} \log (t / 25)\right]
$$

where $D$ is the dose (Sv), $t$ is the time since exposure (years), $e^{*}=(e-30) / 10$ for $e<30$, and $=0$ for $e \geqslant 30$, where $e$ is age at exposure in years; $\beta=1.1$ for males, 1.2 for females; $\gamma=-0.40$ per decade (of age at exposure); $\delta=-0.48 ; \phi=0.42$; and $\theta=0.87$. 
The model is valid only for the period $\geqslant 5$ years following exposure. Therefore, the formula is used to calculate ERR in each age group, assuming annual doses estimated as described above, starting at those aged 5-9 years in 2010, who would have been first exposed at a mean age of 2.5. The BEIR VII committee (NRC, 2006) dealt with recent exposures by assuming that the excess absolute risk in the period 2-5 years following exposure is equal to that observed 5 years after exposure. Therefore, for the youngest age group ( $0-4$ years), we derived the ERR by assuming that the excess absolute risk was the same as that for children aged 5-9 years who had been exposed at (mean) age 2.5. As exposures are assumed to have been occurring since 1950, we assume that the relative risks in each 5 -year age group are multiplicative. That is, the relative risk in children aged 10-14 years in 2010 is the product of that in children exposed for 5 years at (mean) age 7.5 and that in children exposed for 10 years at (mean) age 2.5. As in the BEIR VII report (NRC, 2006), we assumed that the risk of CLL is not influenced by exposure to radiation, so the estimated ERRs were applied to the number of leukaemia cases in the UK, excluding CLL. The proportions of CLL cases among all leukaemia were taken from the published data for England for 2007 (ONS, 2010). We estimate that 7.7 cases of leukaemia in males ( $0.17 \%$ of all leukaemia) and 4.5 in females $(0.14 \%$ of leukaemia cases $)$ might be attributable to exposures received through nuclear medicine.

Adding the solid cancers and leukaemia cases, the total estimate for cancers attributable to radiation received through nuclear medicine exposures in 2010 is 11.5 in males $(0.007 \%$ of all cancers) and 7.9 cancers in females $(0.005 \%$ of all cancers $)$.

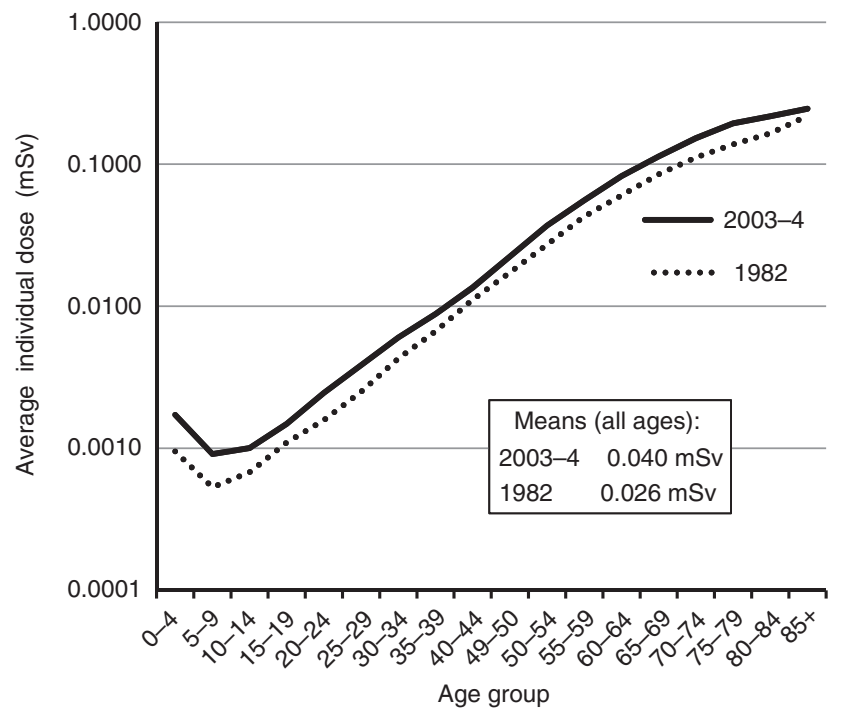

Figure 2 Average individual effective dose to the whole body ( $\mathrm{mSv}$ ), from nuclear medicine practice, 1982 and 2003-4, males and females combined.
Therapeutic radiation Around $3 \%$ of the UK population are cancer survivors, with the total number now around 2 million and increasing by 3\% per annum (Maddams et al, 2009). Many cancer survivors have received radiotherapy, and such treatment usually involves some incidental irradiation of the surrounding normal tissues, thus increasing the risk of a radiation-associated second cancer. Up until now, estimates of the radiation exposure of the UK population have not included exposure from radiotherapy, and the total number of cancers in the UK population associated with past radiation exposure from radiotherapy has not been assessed previously.

Maddams et al (2011) have prepared estimates of the cancer burden in the UK in 2007 due to radiotherapy. The method used was based on estimates of the numbers of cancer survivors in the UK at the beginning of 2007 (by cancer site, sex, age and time since diagnosis), the proportion that had received treatment by radiotherapy, and the relative risk of a second cancer associated with previous radiotherapy (from the United States Surveillance Epidemiology and End Results (SEER) programme (Curtis et al, 2006)). The methodology for preparing estimates of the number of cancer survivors for England is described in Maddams et al (2009); age- and sex-specific population ratios between England and the UK were then used to scale these numbers to a UK level. The radiotherapy proportions from the Thames Cancer Registry were applied to the estimated numbers of cancer survivors in the UK at the beginning of 2007 to provide an estimate of the number who had, and the number who had not, received radiotherapy, by sex, age, cancer site and time since diagnosis (in periods $<1,1-4,5-9$, $10-14,15-19,20-35$ years). The numbers of second cancers associated with radiotherapy were estimated for 13 cancer sites, based on the risk, relative to the general population (of the SEER registry areas), of developing a second cancer, for intervals $<1,0-4,5-9$ and $10+$ years post diagnosis of the first cancer, for cancer survivors who had received radiotherapy $\left(R_{r t+}\right)$ and those who had not $\left(R_{r t-}\right)$. The excess risk of cancer due to radiotherapy, relative to the general population (ERR), is then given by

$$
\mathrm{ERR}=R_{r t+}-R_{r t-}
$$

For each of the 13 cancer sites, the numbers of second cancers expected in the UK during 2010 associated with radiotherapy for a previous cancer were estimated using incidence rates for 2010 in the UK population and the relative risk of a second cancer in cancer survivors. To estimate the total number of second cancers, the numbers estimated to have occurred among survivors of the 13 selected cancer sites were multiplied by the ratio of the number of cancer survivors for all cancers combined to that for just the 13 selected sites combined, by sex, age group and time since diagnosis.

Table 6 shows estimates of the numbers of second cancers (all malignant neoplasms excluding non-melanoma skin cancer) diagnosed in the UK in 2010 among people who had previously been diagnosed with one of the 13 selected sites of the initial cancer.

Table 5 Excess relative risk (\% per Sievert)

Excess relative risks (\% per Sievert) by cancer and sex

\begin{tabular}{|c|c|c|c|c|c|c|c|c|c|c|c|c|c|c|c|c|c|c|c|c|c|}
\hline \multicolumn{2}{|c|}{ Oesophagus } & \multicolumn{2}{|c|}{ Stomach } & \multicolumn{2}{|c|}{ Colon } & \multicolumn{2}{|c|}{ Liver } & \multicolumn{2}{|c|}{ Lung } & \multicolumn{2}{|c|}{ Bone } & \multicolumn{2}{|c|}{ Breast } & \multicolumn{2}{|c|}{ Bladder } & \multicolumn{2}{|c|}{$\begin{array}{c}\text { Brain } \\
\text { and CNS }\end{array}$} & \multicolumn{2}{|c|}{ Thyroid } & \multicolumn{2}{|c|}{$\begin{array}{l}\text { All other } \\
\text { solid cancers }\end{array}$} \\
\hline M & $\mathbf{F}$ & $\mathbf{M}$ & $\mathbf{F}$ & $\mathbf{M}$ & $\mathbf{F}$ & $M$ & $\mathbf{F}$ & M & $\mathbf{F}$ & $M$ & $\mathbf{F}$ & $\mathbf{M}$ & $\mathbf{F}$ & $\mathbf{M}$ & $\mathbf{F}$ & $\mathbf{M}$ & $\mathbf{F}$ & $\mathbf{M}$ & $\mathbf{F}$ & $\mathbf{M}$ & $\mathbf{F}$ \\
\hline 0.68 & 0.39 & 0.44 & 0.21 & 1.44 & 1.21 & 0.16 & 0.11 & 2 & 4.93 & 0.19 & 0.14 & - & 8.88 & 2.08 & 0.73 & 0.41 & 0.29 & 0.16 & 0.44 & 3.87 & 2.4 \\
\hline
\end{tabular}

Abbreviations: CNS, central nervous system; F, female; M, male. Based on United Nations Scientific Committee on the Effects of Atomic Radiation (UNSCEAR) Table 7I (2006). Excess relative risk $=$ relative risk -1 
Table 6 Total numbers of second cancers expected in the UK in 2010, and those associated with the excess risk of cancer due to previous radiotherapy, by site of first cancer ( 13 selected cancer sites)

\begin{tabular}{|c|c|c|c|}
\hline \multirow{2}{*}{$\begin{array}{l}\text { First cancer type } \\
\text { Males }\end{array}$} & \multirow[t]{2}{*}{$\begin{array}{l}\text { Expected number } \\
\text { of second cancers }\end{array}$} & \multicolumn{2}{|c|}{$\begin{array}{l}\text { Number (\%) associated } \\
\text { with radiotherapy } \\
\text { for first cancer }\end{array}$} \\
\hline & & & \\
\hline Oral cavity and pharynx & 243 & 47 & $(19.3)$ \\
\hline Oesophagus & 85 & 8 & $(9.8)$ \\
\hline Stomach & 177 & 1 & $(0.7)$ \\
\hline Colorectal & 1751 & 44 & $(2.5)$ \\
\hline Larynx & 391 & 32 & $(2.5)$ \\
\hline Lung & 422 & 33 & (7.7) \\
\hline Prostate & 2006 & 103 & $(5.1)$ \\
\hline Testes & 217 & 23 & $(10.8)$ \\
\hline Hodgkin lymphoma & 218 & 34 & $(10.8)$ \\
\hline Non-Hodgkin lymphoma & 391 & 2 & $(0.4)$ \\
\hline Total (above 10 sites) & 5899 & 328 & $(5.6)$ \\
\hline \multicolumn{4}{|l|}{ Females } \\
\hline Oral cavity and pharynx & 120 & 20 & $(16.6)$ \\
\hline Oesophagus & 45 & 6 & $(12.7)$ \\
\hline Stomach & 74 & 0 & $(0.4)$ \\
\hline Colorectal & 1248 & 22 & $(1.7)$ \\
\hline Larynx & 51 & 4 & $(1.7)$ \\
\hline Lung & 150 & 8 & $(5.1)$ \\
\hline Breast & 7429 & 626 & $(8.4)$ \\
\hline Cervix uteri & 526 & 90 & $(17.1)$ \\
\hline Corpus uteri & 691 & 61 & $(8.9)$ \\
\hline Hodgkin lymphoma & 145 & 28 & $(19.2)$ \\
\hline Non-Hodgkin lymphoma & 286 & I & $(0.4)$ \\
\hline Total (above II sites) & 10766 & 866 & $(8.0)$ \\
\hline
\end{tabular}

${ }^{a}$ Second cancers exclude those at the same site as the first, except for oral cavity and pharynx, colorectal and contralateral breast cancers. Also excluded are all leukaemias diagnosed within one year of any first cancer and all second cancers of other sites diagnosed within 5 years of any first cancer.

For these 13 sites, we estimate that there would have been 5899 cancers diagnosed in male survivors and 10766 in female survivors and that, of these, $328(5.6 \%)$ in men and $866(8.0 \%)$ in women were associated with radiotherapy. These second cancers exclude those at the same site as the first, except for cancers of the oral cavity and pharynx, colon - rectum and contralateral breast.

The greatest number of second cancers in the UK in 2010 was among female survivors of breast cancer - 7429 cancers, of which $626(8.4 \%)$ were associated with radiotherapy for the initial breast cancer; these represent $52.4 \%$ of the 1194 radiotherapy-associated cancers occurring among survivors of the 13 sites considered. There were also relatively large numbers of cancers occurring among survivors of colorectal cancer (2999: i.e., 1751 in males and 1248 in females) and prostate cancer (2006), although the percentages of these that were associated with radiotherapy were relatively small $(2.2 \%$ and $5.1 \%$, respectively). Of the second cancers that occurred among survivors of cancer of the oral cavity and pharynx, cervix uteri, and Hodgkin lymphoma, over $15 \%$ were estimated to be associated with radiotherapy for the first cancer.

Table 7 summarises the estimated numbers of cancers at different sites occurring in 2010 among the survivors of cancer at any of the 13 selected sites considered, and the numbers of these associated with radiotherapy. The most important among those estimated to be radiation-associated, in terms of numbers of cases, are cancers of the lung (274), oesophagus (159) and female breast (129). In all, $14.7 \%$ of second lung cancers were associated with radiotherapy, as were $31.1 \%$ of the oesophageal cancers. However, only $3.3 \%$ of breast cancers occurring in cancer survivors were radiotherapy-associated.

Table 8 (left-hand columns) shows the distribution of radiotherapy-related second cancers in 2010, in survivors of one of the
Table 7 Expected number of second cancers in 2010, by site of second cancer, in survivors of selected primary cancers, ${ }^{a}$ and those associated with the excess risk of cancer due to radiotherapy for the initial cancer

\begin{tabular}{|c|c|c|c|}
\hline \multirow{2}{*}{$\begin{array}{l}\text { Second cancer type }{ }^{\mathbf{a}} \\
\text { Males }\end{array}$} & \multirow[t]{2}{*}{$\begin{array}{l}\text { Expected number } \\
\text { of second cancers }\end{array}$} & \multicolumn{2}{|c|}{$\begin{array}{l}\text { Number }(\%) \text { associated } \\
\text { with radiotherapy } \\
\text { for first cancer }\end{array}$} \\
\hline & & & \\
\hline Oral cavity and pharynx & 179 & 18 & $(9.9)$ \\
\hline Oesophagus & 280 & 74 & $(26.3)$ \\
\hline Stomach & 178 & 14 & $(7.7)$ \\
\hline Colorectal & 836 & 25 & $(3.0)$ \\
\hline Pancreas & 146 & 3 & $(2.0)$ \\
\hline Larynx & 57 & 4 & $(7.6)$ \\
\hline Lung & 859 & 86 & $(10.0)$ \\
\hline Melanoma of the skin & 154 & 4 & $(2.8)$ \\
\hline Prostate & 751 & 0 & $(0.0)$ \\
\hline Bladder & 318 & 23 & $(7.2)$ \\
\hline Leukaemia & 256 & 0 & $(0.0)$ \\
\hline Other sites & 1886 & 77 & $(4.1)$ \\
\hline$A \| l^{c}$ & 5899 & 328 & $(5.6)$ \\
\hline \multicolumn{4}{|l|}{ Females } \\
\hline Oral cavity and Pharynx & 132 & । & $(0.8)$ \\
\hline Oesophagus & 232 & 85 & $(36.6)$ \\
\hline Stomach & 170 & 19 & $(11.0)$ \\
\hline Colorectal & 1040 & 48 & $(4.6)$ \\
\hline Pancreas & 222 & 10 & $(4.4)$ \\
\hline Lung & 1003 & 188 & $(18.8)$ \\
\hline Melanoma of the skin & 238 & 43 & $(17.9)$ \\
\hline Breast & 3905 & 129 & $(3.3)$ \\
\hline Cervix & 30 & 2 & (7.9) \\
\hline Corpus uteri & 377 & 35 & $(9.3)$ \\
\hline Ovary & 298 & 12 & $(4.1)$ \\
\hline Bladder & 187 & 15 & $(7.9)$ \\
\hline Leukaemia & 218 & 39 & $(18.1)$ \\
\hline Other sites & 2712 & 240 & $(8.8)$ \\
\hline$A \|^{c}$ & 10766 & 866 & $(8.0)$ \\
\hline
\end{tabular}

aprimary cancers as listed in Table 6. 'becond cancers exclude those at the same site as the first, except for oral cavity and pharynx, colorectal and contralateral breast cancers. Also excluded are all leukaemias diagnosed within one year of any first cancer and all second cancers of other sites diagnosed within 5 years of any first cancer. 'Excluding non-melanoma skin cancer.

13 cancers considered, by age group and sex. The numbers are expressed as a percentage of all second cancers, and as a percentage of all cancers registered in the UK population. It also shows (right-hand columns) the estimated total number of radiotherapy-related second cancers occurring: 430 cases in men $(0.26 \%$ of all new cancer cases) and 950 cases in women $(0.60 \%$ of all new cancers).

\section{Other forms of natural background radiation}

As noted in Table 1, apart from radon, ionising radiation exposure comes naturally from cosmic rays, followed by terrestrial sources of gamma radiation, and 'internal' emissions.

Cosmic rays are particles that travel through interstellar space. The sun is a source of some of these particles; others come from exploding stars (supernovas). Exposure is increased by air travel at high altitudes.

The amount of terrestrial radiation from rocks and soils varies geographically depending on their local content of uranium.

'Internal' emissions come from radioactive isotopes in food and water and from the human body itself. Exposures from eating and drinking are due in part to the uranium and thorium series of radioisotopes present in food and drinking water. Carbon-14 is present in all living things, and accumulates in the food chain and 
Table 8 Expected number of second cancers in the UK in 2010 associated with radiotherapy for a previous cancer, by age and sex

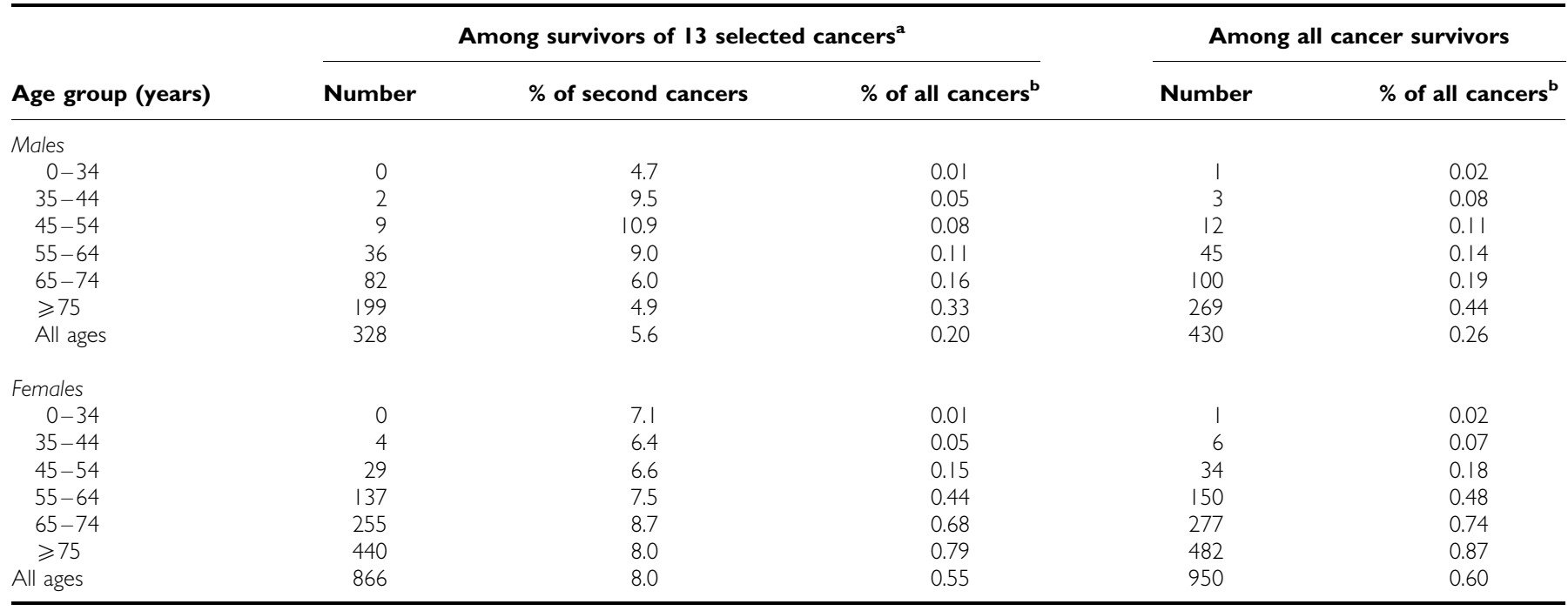

aprimary cancers as listed in Table 6. ' Excluding non-melanoma skin cancer.

Table 9 Excess incidence of solid cancers in 2010 due to background radiation in the UK

\begin{tabular}{|c|c|c|c|c|}
\hline \multirow[b]{2}{*}{ Cancer } & \multicolumn{2}{|l|}{ Males } & \multicolumn{2}{|l|}{ Females } \\
\hline & $\begin{array}{l}\text { Excess } \\
\text { attributable cases }\end{array}$ & $\begin{array}{l}\text { PAF } \\
(\%)\end{array}$ & $\begin{array}{c}\text { Excess } \\
\text { attributable cases }\end{array}$ & $\begin{array}{l}\text { PAF } \\
\text { (\%) }\end{array}$ \\
\hline Oesophagus & 2.4 & 0.04 & 0.7 & 0.03 \\
\hline Stomach & 1.2 & 0.03 & 0.3 & 0.01 \\
\hline Colorectum & 19.6 & 0.09 & 13.5 & 0.08 \\
\hline Liver & 0.2 & 0.01 & 0.1 & 0.01 \\
\hline Lung & 27.7 & 0.12 & 55.6 & 0.31 \\
\hline Bone & $<0.1$ & 0.01 & $<0.1$ & 0.01 \\
\hline Female breast & - & - & 235.5 & 0.49 \\
\hline Bladder & 9.0 & 0.13 & 1.2 & 0.05 \\
\hline Brain and CNS & 0.6 & 0.02 & 0.3 & 0.01 \\
\hline Thyroid & $<0.1$ & 0.01 & 0.3 & 0.02 \\
\hline All other solid ${ }^{\mathrm{a}}$ & 176.6 & 0.23 & 64.2 & 0.14 \\
\hline All solid ${ }^{\mathrm{a}}$ & 237.3 & 0.15 & 371.9 & 0.24 \\
\hline
\end{tabular}

Abbreviations: CNS = central nervous system; PAF = population-attributable fraction. ${ }^{a}$ Excluding non-melanoma skin cancer.

contributes to the internal background dose from ionising radiation.

In estimating the effects of such radiation, we make the simplifying assumption that exposure is uniform throughout the body (rather than concentrated in specific organs), and use the cancer risk estimates, expressed as ERR per unit exposure, from the report of UNSCEAR (2006), as shown in Table 5.

Assuming an average annual dose of $0.93 \mathrm{mSv}$ (Table 1), and a minimum 5-year latency between exposure and the increased risk of solid cancers, the excess incidence of solid cancers (i.e., excluding leukaemias) in the UK in 2010 is shown in Table 9. The total is 609 cases (or $0.2 \%$ of all cancers).

For leukaemia, we used the formula for ERR from BEIR described above in the section on Nuclear Medicine to calculate the relative risk in each age group, assuming an annual exposure of $0.93 \mathrm{mSv}$, starting at those aged 5-9 years in 2010, who would have been first exposed at a mean age of 2.5. For the youngest age group $(0-4$ years $)$, we assumed that the excess absolute risk was the same as that for children aged 5-9 years who had been exposed at (mean) age 2.5 (see above). As exposure is continuous throughout life (rather than a single exposure to radiation at a given age), we assume that the risks in each 5-year age group are multiplicative (i.e., the risk in children aged 10-14 years in 2010 is the product of that in children exposed for 5 years at (mean) age 7.5 and of that in children exposed for 10 years at (mean) age 2.5). The estimated relative risks were applied to the number of leukaemia cases in the UK, excluding CLL.

We estimate that 316 cases of leukaemia in males $(6.8 \%$ of all leukaemia) and 245 in females (7.7\% of leukaemia cases) might be attributable to background radiation. Of these, 81 cases occurred in children aged $<15$ years $(16.6 \%$ of leukaemia cases in this age group).

Adding the solid cancers and leukaemia cases, the total estimate is of 553 radiation-attributable cancers in males $(0.35 \%$ of all cancers) and 617 cancers in females $(0.40 \%$ of all cancers).

\section{Summary of results}

Table 10 shows the sum of the estimated numbers of cancers resulting from exposure to radon, to other forms of natural background radiation and from man-made sources: diagnostic radiology, radiotherapy and nuclear medicine.

In total, we estimate that approximately 5807 of the cancers diagnosed in the UK in 2010 were the result of such exposures, or around $1.8 \%$ of the total.

\section{DISCUSSION}

With respect to cancer causation, these calculations suggest that diagnostic radiology is the most important source of ionising radiation in the UK population. Our estimates are based on the work of Berrington de González and Darby (2004), whose estimates may be slightly high as they assumed that the life expectancy of individuals undergoing diagnostic radiology was the same as that of the general population. Any such overestimation is, however, small compared with the likely underestimation due to the application of risks based on exposures 15 years earlier to calculate the attributable fraction of cancers caused by diagnostic radiation occurring in 2010 . For solid cancers, radiation-related excess risk starts to appear about 5 years after exposure in 
Table 10 Summary of estimated number of cancers in 2010 caused by exposure to ionising radiation, UK

Excess attributable cases

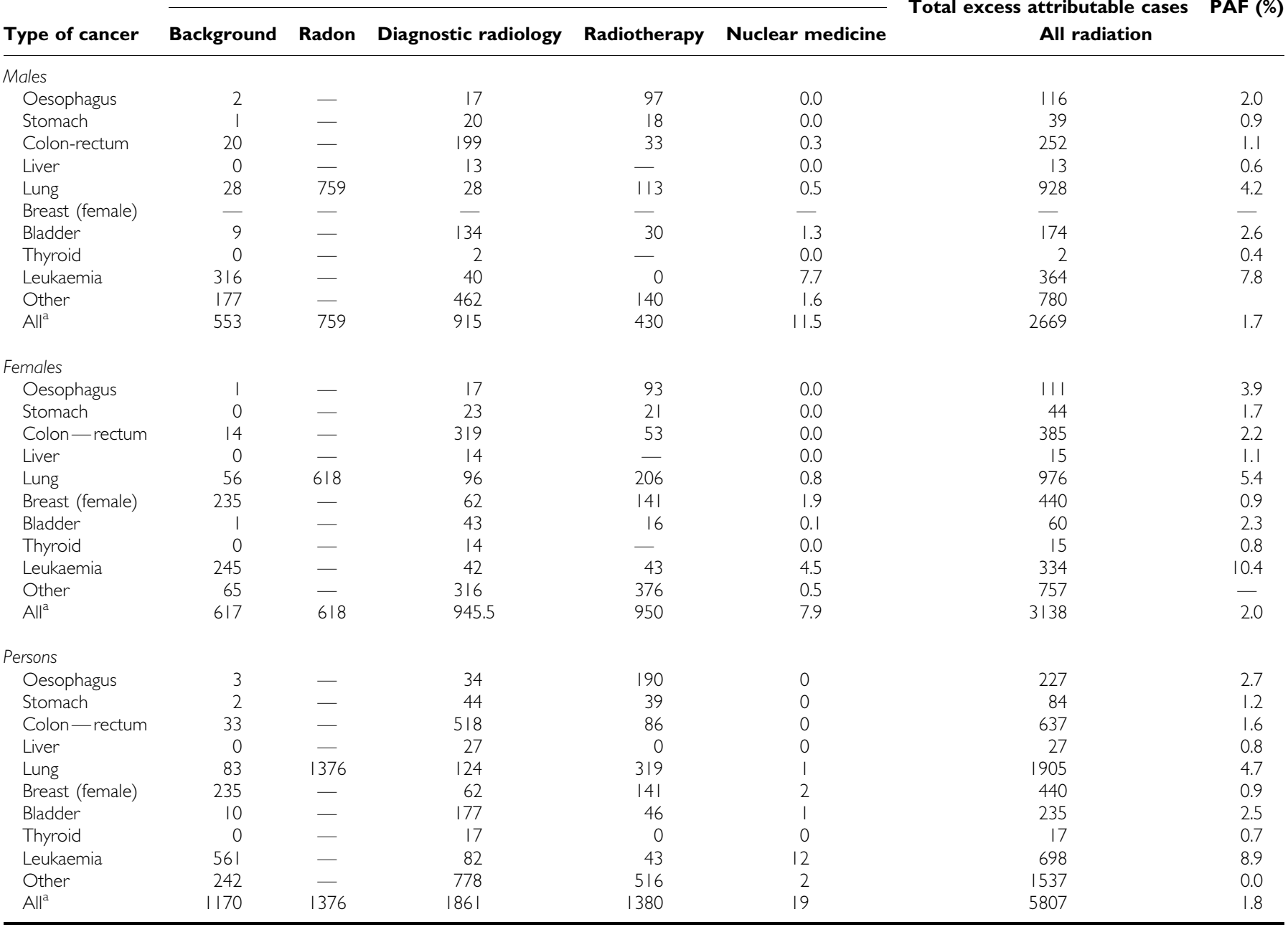

Abbreviation: PAF = population-attributable fraction. ${ }^{a}$ Excluding non-melanoma skin cancer.

therapeutically irradiated groups (Little, 1993; Weiss et al, 1994), while for leukaemia, the increase in risk following exposure certainly starts to appear within 5 years of exposure (Darby et al, 1987); therefore, a more appropriate period of exposure would be some 5-10 years earlier (i.e., 2000-5). The use of X-rays particularly of computerised tomography (CT) scans, which result in higher organ doses of radiation than conventional single-film Xrays - has certainly increased between the period for which Berrington de González and Darby (2004) obtained detailed information on X-ray procedures (1991-6) and 2005. A recent report from the Health Protection Agency (Hart et al, 2010) estimated that the per caput dose from diagnostic radiology was about $400 \mu \mathrm{Sv}$ in 2008, compared with about $330 \mu \mathrm{Sv}$ in 1997-8. The increase is due mainly to the increasing use of CT examinations, which by 2008 accounted for $68 \%$ of the collective dose from all medical and dental X-ray examinations.

Radiation therapy is probably the second most important source of radiation-associated cancer (about one-quarter of the 5807 radiation-attributable cancers). Maddams et al (2011) provide a full discussion of the assumptions and limitations of the estimation, which include the following:

- The total number of survivors in the UK (i.e., the population at risk of a second cancer) is slightly underestimated, as the estimate used includes only those survivors diagnosed up to 35 years previously, although these account for $95 \%$ of all survivors.

- The UK prevalence of individuals with a past diagnosis of cancer who have, or have not, received radiotherapy was inferred from the proportions of cancer survivors who are recorded as having received radiotherapy in the database of the Thames Cancer Registry, and it was assumed that these proportions are reasonably representative of the national situation.

- The estimate of the relative risk of second cancers in survivors who had, and had not, received radiotherapy was derived from the experience of cancer patients in the US SEER population between 1973 and 2000. As radiation treatment was not randomised, selection bias could have resulted in differences between treatment groups with regard to other factors that affect second cancer risk - for example, smoking status, the clinical and pathological features of the initial cancer or concomitant disease.

- It was assumed that the nature of radiotherapy treatment for a given cancer was broadly similar in the US and the UK in the same time period (diagnosis of the initial cancer in 1973-2000).

- Estimation was based on data on prevalence and relative risk of radiotherapy for 13 specific cancer types, and the estimate for all cancer survivors involved a further assumption: that the rate of radiation-associated cancers among the sites not considered 
(25\% of prevalent cancers with past radiotherapy in men, $10 \%$ in women) was similar to that among those that were.

In addition, the estimate for 2010 is based on the assumption that the prevalence of cancer at the beginning of 2010 was the same as at the beginning of 2007 (as in Maddams et al, 2011). In fact, it is likely that prevalence would have increased somewhat in the intervening 3 years, due to increasing incidence, especially of cancers with a good prognosis (breast, large bowel, prostate), and improvements in survival.

Radiotherapy may also be the cause of some other long-term effects, such as an increased risk of cardiovascular disease. However, any long-term side effects of radiotherapy should always be considered in the context of the considerable benefits in terms of control of symptoms and disease.

The estimated number of cases of lung cancer resulting from exposure to radon includes those cases that are the consequence of both smoking and radon exposure and, since their joint effects are multiplicative (Darby et al, 2005), the great majority of such cases occur in smokers, and could be avoided by smoking cessation. Nevertheless, it has been demonstrated that policies requiring basic preventive measures against radon in all new homes throughout the UK would be cost effective and could complement existing policies to reduce smoking (Gray et al, 2009). In contrast, policies involving the identification of existing homes with high radon levels are much less cost-effective and can do little to prevent most radon-related deaths, as these are caused by moderate exposure in many homes.

Most exposure to natural background radiation is not, in practice, avoidable. It is a cause of about one in five radiationinduced cancers, almost half of which are leukaemias. Wakeford et al (2009) have recently published an estimate of the fraction of childhood leukaemia cases that might be attributable to natural background radiation. The precise result depended on the model used to estimate risk in the UK population, based on the results of the life span study of A-bomb survivors, but it is around 20\% (in line with an earlier estimate (Wakeford, 2004)). The result of our rather more simplistic estimation approach $(17 \%)$ is very similar, despite the assumption that the bone marrow dose of radiation from natural sources is constant throughout life. In fact, the radiation dose to the bone marrow of children - especially from ingested sources - is some $20-40 \%$ higher (depending on age) than in adults (Kendall et al, 2009), so that our estimates (and those of Wakeford et al, 2009) may be a little conservative. In any event, the small contribution of childhood leukaemia to the total of radiation-related cancer means that such adjustments will have almost no effect on the totals in Table 10 .

As we describe in the sections related to Methodology, the estimates of population exposure levels (dose) of radiation from the various sources considered rely on many extrapolations and assumptions. Furthermore, we take the conventional view that the relationship between cancer risk and dose at low levels of exposure follows that observed at higher levels, with no threshold effect, although there is very little direct evidence on this point. Despite these limitations, we believe that the overall estimate of around 5000 radiation-induced cancers in the UK (about $2 \%$ of the total) is of the correct order of magnitude.

See acknowledgements on page Si.

\section{Conflict of interest}

The authors declare no conflict of interest.

\section{REFERENCES}

Berrington de González A, Darby S (2004) Risk of cancer from diagnostic X-rays: estimates for the UK and 14 other countries. Lancet 363: $345-51$

Curtis RE, Freedman DM, Ron E, Ries LAG, Hacker DG, Edwards BK, Tucker MA, Fraumeni Jr JF (eds). (2006) New Malignancies Among Cancer Survivors: SEER Cancer Registries, 1973-2000. NIH Publication No. 05-5302. National Cancer Institute: Bethesda, MD

Darby SC, Doll R, Gill SK, Smith PG (1987) Long term mortality after a single treatment course with X-rays in patients treated for ankylosing spondylitis. Br J Cancer 55: 179-190

Darby S, Hill D, Auvinen A, Barros-Dios JM, Baysson H, Bochicchio F, Deo H, Falk R, Forastiere F, Hakama M, Heid I, Kreienbrock L, Kreuzer M, Lagarde F, Mäkeläinen I, Muirhead C, Oberaigner W, Pershagen G, Ruano-Ravina A, Ruosteenoja E, Schaffrath Rosario A, Tirmarche M, Tomášek L, Whitley ER, Wichmann H-E, Doll R (2005) Radon in homes and risk of lung cancer: collaborative analysis of individual data from 13 European case-control studies. $\mathrm{Br}$ Med J 330: 223-228

Darby S, Hill D, Deo H, Auvinen A, Barros-Dios JM, Baysson H, Bochicchio F, Falk R, Farchi S, Figueiras A, Hakama M, Heid I, Hunter N, Kreienbrock L, Kreuzer M, Lagarde F, Mäkeläinen I, Muirhead C, Oberaigner W, Pershagen G, Ruosteenoja E, Rosario AS, Tirmarche M, Tomásek L, Whitley E, Wichmann HE, Doll R (2006) Residential radon and lung cancer - detailed results of a collaborative analysis of individual data on 7148 persons with lung cancer and 14208 persons without lung cancer from 13 epidemiologic studies in Europe. Scand J Work Environ Health 32(Suppl 1): 1-83

Gray A, Read S, McGale P, Darby S (2009) Lung cancer deaths from indoor radon and the cost effectiveness and potential of policies to reduce them. Br Med J 338: a3110

Hart D, Wall BF (2005) A Survey of Nuclear Medicine in the UK in 2003/04. HPA-RPD-003. Health Protection Agency: Chilton, England

Hart D, Wall BF, Hillier MC, Shrimpton PC (2010) Frequency and Collective Dose for Medical and Dental X-ray Examinations in the UK, 2008. HPACRCE-012. Health Protection Agency: Chilton, England

Hughes JS, Watson SJ, Jones AL, Oatway WB (2005) Review of the radiation exposure of the UK population. J Radiol Prot 25: 493-496
International Agency for Research on Cancer (IARC) (2000) IARC Monographs on the Evaluation of Carcinogenic Risks to Humans. Vol. 75, Ionizing Radiation, Part 1: $X$ - and Gamma ( $\gamma$ )-Radiation and Neutrons. IARC: Lyon International Agency for Research on Cancer (IARC) (2001) IARC Monographs on the Evaluation of Carcinogenic Risks to Humans. Vol. 78, Ionizing Radiation, Part 2: Some Internally Deposited Radionuclides. IARC: Lyon

International Commission on Radiological Protection (ICRP) (1988) Radiation dose to patients from radiopharmaceuticals. ICRP Publication 53. Ann ICRP 18: $1-4$

International Commission on Radiological Protection (ICRP) (1998) Radiation doses to patients from radiopharmaceuticals (Addendum to ICRP Publication 53). ICRP Publication 80. Ann ICRP 28: 1-137

International Commission on Radiological Protection (ICRP) (2007) The 2007 Recommendations of the International Commission on Radiological Protection. ICRP Publication 103. Ann ICRP 37: 2-4

Kendall GM, Fell TP, Harrison JD (2009) Dose to red bone marrow of infants, children and adults from radiation of natural origin. J Radiol Prot 29: $123-138$

Little MP (1993) Risks of radiation-induced cancer at high doses and dose-rates. J Radiol Prot 13: 3-25

Maddams J, Brewster D, Gavin A, Steward J, Elliott J, Utley M, Moller H (2009) Cancer prevalence in the United Kingdom: estimates for 2008. Br J Cancer 101: $541-547$

Maddams J, Parkin DM, Darby S (2011); The cancer burden in the UK in 2007 due to radiotherapy. Int J Cancer 129: 2885-2893

National Research Council (NRC) (2006) Health Risks from Exposure to Low Levels of Ionizing Radiation: BEIR VII - Phase 2. Committee to Assess Health Risks from Exposure to Low Levels of Ionizing Radiation, National Academy of Sciences. National Academies Press: Washington, DC

Office of National Statistics (ONS) (2010) Cancer Statistics Registrations. Registrations of Cancer Diagnosed in 2007, England. Series MB1 No. 38 Office for National Statistics: Newport. http://www.ons.gov.uk/ons/ publications/re-reference-tables.html?edition $=\mathrm{tcm} \% 3 \mathrm{~A} 77-156482$

United Nations Scientific Committee on the Effects of Atomic Radiation (UNSCEAR) (2000) Sources and Effects of Ionizing Radiation. United Nations: New York 
United Nations Scientific Committee on the Effects of Atomic Radiation (UNSCEAR) (2006) Effects of Ionizing Radiation. UNSCEAR 2006 Report to the General Assembly, with Scientific Annexes. United Nations: New York

Wakeford R (2004) The cancer epidemiology of radiation. Oncogene 23: 6404-6428

Wakeford R, Kendall GM, Little MP (2009) The proportion of childhood leukaemia incidence in Great Britain that may be caused by natural background ionizing radiation. Leukemia 23: 770-776

Weiss HA, Darby SC, Doll R (1994) Cancer mortality following x-ray treatment for ankylosing spondylitis. Int J Cancer 59: 327-338
Wrixon AD, Green BMR, Lomas PR, Miles JCH, Cliff KD, Francis EA, Driscoll CMH, James MC, O'Riordan MC (1988) Natural Radiation Exposure in UK Dwellings. Report No. NRPB-R190. National Radiological Protection Board: Chilton, England

(c) (i) (2) This work is licensed under the Creative Commons CY NG SA Attribution-NonCommercial-Share Alike 3.0 Unported License. To view a copy of this license, visit http://creativecommons. org/licenses/by-nc-sa/3.0/ 